\title{
Cerebral malaria: insight into pathogenesis, complications and molecular biomarkers
}

This article was published in the following Dove Press journal:

Infection and Drug Resistance

2 February 2017

Number of times this article has been viewed

\author{
Farah Hafiz Yusuf' \\ Muhammad Yusuf Hafiz' \\ Maria Shoaib' \\ Syed Ahsanuddin Ahmed ${ }^{2}$ \\ 'Department of Medicine, Dow \\ Medical College, Dow University \\ of Health Sciences, ${ }^{2}$ Department of \\ Medicine, Sindh Medical College, \\ Jinnah Sindh Medical University, \\ Karachi, Pakistan
}

\begin{abstract}
Cerebral malaria is a medical emergency. All patients with Plasmodium falciparum malaria with neurologic manifestations of any degree should be urgently treated as cases of cerebral malaria. Pathogenesis of cerebral malaria is due to damaged vascular endothelium by parasite sequestration, inflammatory cytokine production and vascular leakage, which result in brain hypoxia, as indicated by increased lactate and alanine concentrations. The levels of the biomarkers' histidine-rich protein II, angiopoietin-Tie-2 system and plasma osteoprotegrin serve as diagnostic and prognostic markers. Brain imaging may show neuropathology around the caudate and putamen. Mortality is high and patients who survive sustain brain injury which manifests as long-term neurocognitive impairments.
\end{abstract}

Keywords: cerebral malaria, neurologic manifestations, mortality, biomarkers, brain imaging

\section{Introduction}

One of the most fretful complications and leading causes of death due to infection with Plasmodium falciparum is cerebral malaria, accounting for around $13 \%$ of all malaria-related deaths. ${ }^{1}$ It is life threatening especially in children due to their underdeveloped defense mechanism. ${ }^{2}$ Malaria itself has a high death toll among communicable diseases.

\section{Discussion}

Cerebral malaria is a medical emergency demanding urgent clinical assessment and treatment. Altered consciousness, convulsions, ataxia, hemiparesis and other neurologic and psychiatric impairments should raise the possibility of cerebral malaria. ${ }^{3}$ The diagnosis requires presence of neurologic symptoms and asexual forms of the parasite on peripheral blood smears. It is important to exclude other causes of encephalopathy (e.g., hypoglycemia, bacterial meningitis and viral encephalitis) and Glasgow Coma Scale score of 9 or less which depicts an already determined significant unconscious state due to any other cause. ${ }^{4}$ To distinguish cerebral malaria from transient postictal coma, unconsciousness should persist for at least $30 \mathrm{~min}$ after a convulsion. Coma depicts worse prognosis. All patients with $P$. falciparum malaria with neurologic manifestations of any degree should be treated as cases of cerebral malaria.

Pathogenesis of cerebral malaria is due to damaged vascular endothelium by parasite sequestration, inflammatory cytokine production and vascular leakage. The
Correspondence: Maria Shoaib Dow Medical College, Dow University of Health Sciences, I76/Y Block 2 PECHS, Karachi 75400, Pakistan

Tel +923333289909

Email syedamariashoaib@gmail.com 
basic underlying defect seems to be clogging of the cerebral microcirculation by the parasitized red cells as a result of increased cytoadherent properties due to which the parasites sequester in these deeper blood vessels. Also, rosetting of both healthy and infected red cells further impairs healthy circulation. This results in hypoxia and brain ischemia as depicted by increased lactate and alanine concentrations along with decreased aspartate and adenosine triphosphate levels. ${ }^{4,5}$

Another feature of $P$. falciparum infection is production and secretion of histidine-rich protein II which now serves as a diagnostic and prognostic marker for falciparum malaria; high levels have been associated with breach in the blood brain barrier giving in to the parasite. ${ }^{6}$ The association with hypoxia, as well as the cytokine expression to play a role in its evolvement, especially interferon- $\gamma$ and lymphotoxin- $\alpha$, and the chemokine CXCL10 are essential for the development of cerebral malaria. ${ }^{7}$ Natural killer cells are among the early recruits to the brain, stimulating $T$ cell recruitment to the affected brain. This provides evidence that immune responses mediated by natural killer cells can also regulate adaptive immunity by modulating the ability of $\mathrm{T}$ lymphocytes to migrate to the site of inflammation in response to chemotactic stimuli. ${ }^{8}$

Angiopoietin-Tie-2 system is a critical regulator of vascular function and has association with the disease severity and outcome. ${ }^{9}$ The early and marked increase in plasma osteoprotegrin levels is linked with malaria, which may represent an epiphenomenon, consistent with acute endothelial cell activation and Weibel Palade body secretion. ${ }^{10}$

Identification of such novel malaria biomarkers that could be utilized as diagnostic or therapeutic targets is becoming increasingly important. ApoE is a major apolipoprotein in the brain and has been found to be dominant in several neurologic disorders; therefore, possible significance of ApoE in cerebral malaria was studied. The absence of ApoE conferred a protection against it, with decreased sequestration of parasites and $\mathrm{T}$ cells within the brain as observed in a mice model. ${ }^{11}$

Mortality is high and patients who survive sustain brain injury which manifests as long-term neurocognitive impairments like difficulty in speaking, memory impairments, attention span, visual spatial skills and executive function to a more severe intensity. ${ }^{12}$ Other common complications of cerebral malaria, such as convulsions, hypoglycemia and hyperpyrexia, should be prevented or detected and treated early. Fluid, electrolyte and acid-base balance may need correction. Skilled nursing care of the unconscious patient is crucial. Ancillary treatments should be avoided unless they have proved safe and effective.
Combinations of adjuvant therapies targeting specific mechanisms of brain injury may be needed to improve the neurocognitive outcome. ${ }^{4}$ Lowering the lactate levels by using dichloroacetate has been shown to improve survival. ${ }^{5}$ Magnetic resonance imaging/computed tomography brain imaging may provide important insights into pathogenesis. Imaging studies can depict structural changes such as cerebral edema with hypoattenuation of the thalamus and the cerebellum. Usually, the brain volume is found to be slightly more during acute cerebral malaria than during the convalescent phase of the disease. This finding is attributed to an increase in the volume of intracerebral blood caused by sequestration of parasitized red cells and compensatory vasodilatation, rather than by edema alone. ${ }^{13}$ Frequently, neuropathology is noticed around caudate and putamen and its adjacent areas (corpus callosum, hippocampus, etc). The online connectomics "Gogli" is a handy tool for structural study to assess the molecules and cells. The few detected molecules during the disease phase are alpha 3 subunit nicotinic receptor, beta 2 subunit nicotinic receptor and sulfhydryl oxidase and the cells are Purkinje neuron, cerebellar granule cell and Golgi neuron. The identified molecules and cells are potential targets for further research on the pathophysiology of cerebral malaria. They could be promising disease markers and apoptotic or necrotic factors for the infected cells. Novel drugs and treatment can target these identified molecules and their metabolic pathways to detect and alleviate the neurologic symptoms and the disease. ${ }^{14}$

\section{Conclusion}

Despite the complex mechanism and factor interplay known so far, still it is not sufficient to influence the mortality rate to a significant extent, as the neurologic sequel, convulsions, coma and severe anemia are known to affect most of the patients. ${ }^{1}$ Moreover, the disease itself is unpredictable and the complications it can manifest are unforeseen. What can be offered is simple prevention like mosquito control and antimalarial prophylaxis in the endemic areas and aggressive measures in the initial phase which may probably change the outcome and long-term prognosis.

\section{Disclosure}

The authors report no conflicts of interest in this work.

\section{References}

1. Mundhra S, Parmar U, Shukla D. A prospective study to identify the co-relation of a disease severity of complicated malaria \& clinical outcome. Paripex-Ind J Res. 2016. 12;4(7).

2. Gay F, Zougbédé S, N'dilimabaka N, Rebollo A, Mazier D, Moreno A. Cerebral malaria: what is known and what is on research. Revue neurologique. 2012;168(3):239-256. 
3. Newton CR, Hien TT, White N. Cerebral malaria. J Neurol Neurosurg Psychiatry. 2000;69(4):433-441.

4. Idro R, Marsh K, John CC, Newton CR. Cerebral malaria: mechanisms of brain injury and strategies for improved neurocognitive outcome. Pediatric Res. 2010;68(4):267-274.

5. Miller LH, Baruch DI, Marsh K, Doumbo OK. The pathogenic basis of malaria. Nature. 2002;415(6872):673-679.

6. Pal P, Daniels BP, Oskman A, Diamond MS, Klein RS, Goldberg DE. Plasmodium falciparum histidine-rich protein ii compromises brain endothelial barriers and may promote cerebral malaria pathogenesis. mBio. 2016;7(3):e00617-16.

7. Bakmiwewa SM, Weiser S, Grey M, Heng B, Guillemin GJ, Ball HJ, Hunt NH. Synergistic induction of CXCL10 by interferon-gamma and lymphotoxin-alpha in astrocytes: Possible role in cerebral malaria. Cytokine. 2016;78:79-86.

8. Mundhra S, Parmar U, Shukla D. A Prospective Study to Identify the Co-Relation of a Disease Severity of Complicated Malaria \& Clinical Outcome. PARIPEX-Indian J Res. 2016;4(7).
9. Pal P, Daniels BP, Oskman A, Diamond MS, Klein RS, Goldberg DE Plasmodium falciparum histidine-rich protein II compromises brain endothelial barriers and may promote cerebral malaria pathogenesis. MBio. 2016;7(3):e00617-16.

10. O'Regan N, Moxon C, Gegenbauer K, et al. Marked elevation in plasma osteoprotegerin constitutes an early and consistent feature of cerebral malaria. Thromb Haemost. 2016;115(4):773-780.

11. Kassa FA, Van Den Ham K, Rainone A, Fournier S, Boilard E, Olivier $\mathrm{M}$. Absence of apolipoprotein $\mathrm{E}$ protects mice from cerebral malaria Sci Rep. 2016;6:33615.

12. Idro R, Carter JA, Fegan G, Neville BG, Newton CR. Risk factors for persisting neurological and cognitive impairments following cerebral malaria. Arch Dis Child. 2006;91(2):142-148.

13. Gupta S, Patel K. Case series: MRI features in cerebral malaria. Indian J Radiol Imaging. 2008;18(3):224.

14. Wiwanitkit S, Joob B, Wiwanitkit V. Cerebral malaria: an interactive brain mapping study. Asian Pac J Trop Med. 2016;9(8):823.
Infection and Drug Resistance

\section{Publish your work in this journal}

Infection and Drug Resistance is an international, peer-reviewed openaccess journal that focuses on the optimal treatment of infection (bacterial, fungal and viral) and the development and institution of preventive strategies to minimize the development and spread of resistance. The journal is specifically concerned with the epidemiology of antibiotic

\section{Dovepress}

resistance and the mechanisms of resistance development and diffusion in both hospitals and the community. The manuscript management system is completely online and includes a very quick and fair peerreview system, which is all easy to use. Visit http://www.dovepress.com/ testimonials.php to read real quotes from published authors.

Submit your manuscript here: https://www.dovepress.com/infection-and-drug-resistance-journal 